\title{
Optimality account of the decomposition of fricatives
}

\author{
Sang Cheol Ahn' ${ }^{1}$ Kyunney Egorova ${ }^{2, *}$ \\ ${ }^{1}$ North-Eastern Federal University named after M.K. Ammosov, 58, Belinskogo st., Yakutsk, 677000, Russia \\ ${ }^{2}$ North-Eastern Federal University named after M.K. Ammosov, 58, Belinskogo st., Yakutsk, 677000, Russia
}

\begin{abstract}
This paper analyzes various cases of consonantal decomposition in interlanguage mapping within the framework of Optimality Theory. During the analyses, we argue that the preservation of the (major) place property takes the most crucial role in the segmental decomposition in interlanguage mapping. As for the Japanese adaptation of /f/ which is adapted as $<\mathrm{h}>$ (orthographically at least) lacking labiality, we posit this Japanese fricative as $/ \phi /[1]$ preserving the labiality and show the inviolability of the constraint Max-Place. Then we compare the indirect adaptation of the English /f/, i.e., via Anglo-Japanese / $\phi$ /, with the direct loan adaptation in Korean. In the indirect (old) adaptation, the labial fricative $/ \phi /$ is decomposed as the fricative $/ \mathrm{h} /$ and the labial vowel /u/ (or/w/) (e.g., /申uri:/フリ $\rightarrow$ /huri/ 'free' 후리), while the direct (new) loan pattern shows the $/ \mathrm{f} / \rightarrow / \mathrm{p}^{\mathrm{h}} /$ mapping (e.g., / $/ \mathrm{p}^{\mathrm{h}}$ iri/ 'free' 프리). Here we observe not only the inviolability of Max-Place but also the demotion of Ident[cont] at the level of direct loan adaptation. We thus claim that our current analysis supports the Stratal OT [2], regarding the levels of adaptation. As for the inviolability of Max-Place, we also discuss how the Russian /f/ is decomposed in the loan adaptation in Yakut (e.g., Fjodor $\rightarrow$ /syøder/ 'male name')..
\end{abstract}

\section{Introduction}

Loan adaptation often triggers phonemic mapping as the recipient and target language may differ in phonemic inventories. And the mapping mostly occurs between the two most similar sounds phonetically or perceptually $[3,4,5,6,7,8]$. In the adaptation of fricatives or affricates, however, we often find the cases of merge or decomposition, i.e., two segments $\rightarrow$ one segment or one segment $\rightarrow$ two segments. This paper analyzes various cases of consonantal decomposition in interlanguage mapping. As shown in Campbell, a new phoneme may appear diachronically via phonological decomposition. For example, the French $/ 3 /$ was adapted as $/ z /+/ j /$ in the beginning but became a new phoneme later in English. To this end, we will employ the framework of Optimality Theory (McCarthy \& Prince 1995, McCarthy 2008) and show how the decomposition can be better explained in this framework, based on constraint ranking and interaction. During the analyses, we will show that the preservation of the place property takes the most crucial role in the segmental decomposition in interlanguage mapping, while other properties such as [cont] may not be preserved.

In Japanese loan adaptation, the English labial fricative /f/ is known to be adapted as $\langle\mathrm{h}\rangle$ (orthographically at least) which lacks the labiality. The possible loss of the labiality brings us the issue on the internal structure of the Japanese fricative and the status of Max-Place requiring that the place property of the input be present somewhere in the output.

In Korean loan adaptation, there are many cases of indirect English loans, i.e., borrowing from AngloJapanese words. And the output forms of the indirect loans and those of direct loans are often quite different, although Max-Place is still inviolable. For this difference, we will compare the indirect and direct adaptation patterns of the English /f/ within the framework of Optimality Theory and see if the current OT framework is suitable for the explanation on the difference.

Furthermore, we need to examine if the inviolability of Max-Place can be extended to other languages or other consonants. We will thus examine how the Russian /f/ is decomposed in the loan adaptation in Yakut (e.g., Fjodor $\rightarrow$ /syøder/ 'male name'). We further argue that the dominance of the Max-Place in decomposition applies to other place properties, Coronal, more specifically palatality, and Dorsal. We will discuss the decomposition of the nasal $/ \mathrm{n} /$ and the fricative $/ \delta /$ in Korean adaptation (i.e., $/ \mathrm{j} / \rightarrow / \mathrm{n} /+/ \mathrm{j} /$ and $/ \mathrm{g} / \rightarrow / \mathrm{s} /+/ \mathrm{j} /$ ). Then, we will extend our discussion to the decomposition of the Russian velar fricative / $\mathrm{x} /$ (as / $/ \mathrm{k} /+$ $/ \mathrm{h} /$ ) in Korean loan adaptation, showing the dominance of Max-Place (i.e., Dorsal). 


\section{Background}

\subsection{Decomposition}

Segmental decomposition is can be realized in two ways, i.e., vocalic and consonantal. Diphthongization, for example, is a typical case of decomposition of vowel. For example, Korean vowel system underwent the diphphongization process since the $16^{\text {th }}$ century, so that the earlier monophthongs /ü, ö/ became /wi, we/ in Modern Korean [9]. This type of diphthongization also occurs often in loan adaptation, e.g., Russian stressed vowel /u/ $\rightarrow$ Yakut /uo/.

On the other hand, a typical case of consonantal decomposition and merger can be found in the interlanguage mapping of fricatives/affricates in many languages. The voiceless fricative /f/ is, for example, often decomposed during the process of loan adaption in the languages lacking this fricative as a phoneme. For example, the English fricative /f/ in "coffee" corresponds to the Arabic /hw/ and the Turkish /hv/ [10].

(1) English /f/ 'coffee' <-> Turkish kahveh, Arabic qahwah 'infusion, beverage'

The $/ \mathrm{hv} /$ or $/ \mathrm{hw} /$ sequence of these languages was later adapted as /f/ in many Indo-European languages through the merge of two different phonetic components (probably due to the phonotactic constraint prohibiting /hw/ or /hv/ sequence), i.e., not only the continuancy of airflow and but also the labiality. Again, in a later historical period, the fricative /f/ was decomposed as /h/ $+/ \mathrm{v} /$ in Finnish. This decomposition seems to occur only in old loan words as the foreign /f/ is now adapted as the corresponding /f/ in Finnish: e.g., caffeine $\rightarrow$ kofeiini.

\section{(2) Finnish loanword: kahvi 'coffee'}

This example indicates that the inserted labial /v/ provides the labiality to the output as the glottal fricative /h/ does not hold any place property.
(3) $/ \mathrm{hv} /$

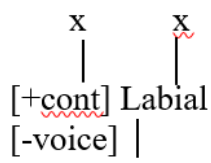

vs.

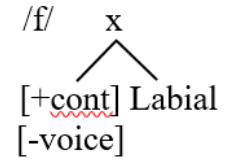

\subsection{Optimality constraints}

Optimality Theory (McCarthy \& Prince 1995, McCarthy 2008) assumes the input-output correspondence relationship based on three basic faithfulness constraints.

(4) Max Input segments must have output correspondents.

Dep Output segments must have input correspondents.

Ident $[\alpha \mathrm{F}]$ Correspondent segments in input and output have identical values for $[\alpha \mathrm{F}]$
The faithfulness constraints are, however, often violated by certain markedness constraints. Markedness constraints require that output forms meet some criterion of structural well-formedness. In every grammar, therefore, two major forces are inherently engaged in a fundamental conflict. Markedness constraints exert pressure toward unmarked structures but this force is counter-balanced by faithfulness constraints preserving lexical contrasts. For example, many languages like Japanese, Korean or Yakut has a very simple structure, so vowels are inserted for the adaptation of loan words with complex syllable structures, thus violating Dep, e.g., English cream $\rightarrow / \mathrm{k}^{\mathrm{h}}$ irim/ in Korean and /kurimu/ in Japanese.

Along with the faithfulness constraints, many markedness constraints play important roles, complying with the phonotatics in a specific language. For example, the following constraints represent a couple of typical markedness constraints discouraging an initial $/ \mathrm{p} /$ or a consonant cluster in Yakut.

(5) \#p: An initial /p/ may not surface.

*CC: Consonant clusters may not be allowed.

Besides these basic markedness constraints, there are other important constraints which are reflected in the adaptation of loanwords. The following tableau illustrates how the optimal output is selected by the constraint interaction in a Japanese example of loan adaptation, where the final candidate $(6 \mathrm{~d})$ is selected as the optimal output in spite of the violation of the lowest ranking faithfulness constraint Dep.

(6)

\begin{tabular}{|c|c:c:c|c|}
\hline kri:m & $*$ CC & NoCoda & Max & Dep \\
\hline \hline a. kri:m & $* !$ & $*$ & & \\
\hline b. kuri:m & & $* !$ & & $*$ \\
\hline c. kuri: & & & $* !$ & \\
\hline d. kuri:mu & & & & $* *$ \\
\hline
\end{tabular}

\section{Adaptation of $/ \mathbf{f} /$ and place preservation}

\subsection{Place preservation in the adaptation of} /f/ in Japanese

As shown in the literature [Silverman 1992, Paradis \& LaCharité 1997, Peperkamp \& Dupoux 2003, LaCharité \& Paradis. 2005, Ahn \&Lee 2011, Lee et al. 2016 etc.], the segment of the target language should be realized as a corresponding segment in the recipient language and they share the common phonetic or phonological properties. The English $/ \theta /$, for example, is mapped to $/ \mathrm{s} /$ in Japanese loan adaptation, showing the preservation of the major place property, i.e., coronality. The mapping relation can be shown in the optimality framework with several relevant constraint ranking relationships.

(7) *Struct Non-phonemic segment are prohibited.

Max-Place Major Place property (i.e., Labial, Coronal, Dorsal) should be preserved. 
Ident $[\mathrm{F}]$ The input feature $[\mathrm{F}]$ should be present in the output.

The following evaluation tableau shows that $*$ Struct prohibits the appearance of the non-phonemic segment $/ \theta /$ and Max-Place requires the realization of the major place category (i.e., coronality) of the input in the output. Ident[cont] requires the realization of the [cont] feature of the fricative, while Ident[place] requiring the preservation of the input place property. The following tableau shows that the major place feature, coronality, remains intact in the optimal candidate.

\begin{tabular}{|l|l:l:l|l|}
\hline$\theta$ & *Str & Max & Ident[con & Ident[denta \\
& uct & - & t] & l] \\
& & Plac & & \\
\hline a. $\theta$ & $* !$ & & & \\
\hline b. h & & $* !$ & & $*$ \\
\hline c. s & & & & $*$ \\
\hline d. t & & & $* !$ & $*$ \\
\hline
\end{tabular}

In the adaption of /f/ in Japanese, however, this common tendency of place preservation seems to be violated as the English /f/ corresponds to /h/ in Japanese, at least orthographically. The following examples (9) show that both Japanese and Korean lack /f/ phonemically and the English /f/ is adapted as a single fricative in Japanese, while as a labial stop $/ \mathrm{p}^{\mathrm{h}} /$ in (Modern) Korean. As $/ \mathrm{h} /$ does not have any place property, Japanese speakers seem to lose the labiality of /f/ in loan adaptation.

\section{(9) 'coffee' $/ \mathrm{k}^{\mathrm{h}}$ э:fi/ $\rightarrow$ Japanese: (コーヒー) kōhii \\ 'caffeine' \\ (カフェイン) kahueiN \\ (cf. Korean: $k^{h} \partial p^{h} i, k^{h} a p^{h} e i n$ )}

Following Iverson [1], however, we argue that the Japanese $/ \mathrm{h} /$ has both continuancy and labiality underlying. Iverson [1] claims that the underlying representation of the Japanese $/ \mathrm{h} /$ is in fact $/ \phi /$ which surfaces as $[\phi]$ before $/ \mathrm{u} /$, while $[\mathrm{h}]$ elsewhere. (Thus, the foreign /f/ is adapted as $[\phi]$ before $/ \mathrm{u} /$ but as $[\mathrm{h}]$ in other cases). Based on the framework of Feature Geometry [11, 12], the following figures show the difference between the Japanese $h$, i.e., $/ \phi /$, and $/ \mathrm{h} /$ in other languages.
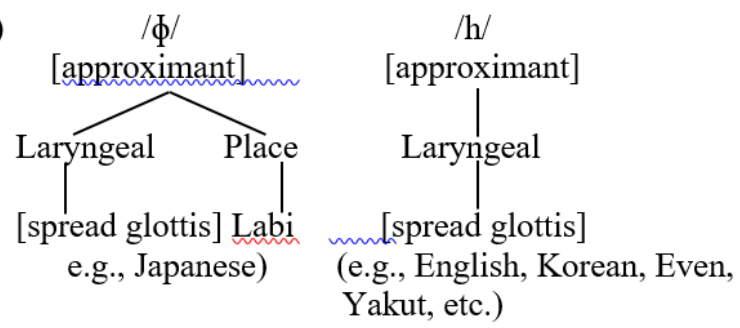

Iverson [1] claimed that interlanguage sound substitution often reveals the underlying representation of a phoneme. The phonemic status of the Japanese voiceless approximant $/ \phi /$ (rather than $/ \mathrm{h} /$ ) can be verified as $/ \phi /$ substitutes for target /f/ irrespective of environment, similar to the case of [s] substitution for target $/ \theta$ / irrespective of environment.

(11) labio-dental fricative /f/ $\rightarrow$ labial fricative $/ \phi /$

Showing this mapping relationship, the following evaluation tableau illustrates how the optimal output segments is selected. First, *Struct prohibits the appearance of the non-phonemic segment /f/, while MaxPlace requires the realization of the major place category (i.e., labiality) of the input in the output. Then, Ident[cont] indicates the realization of the [cont] feature of the fricative and Ident[place] requires the realization of the [dental] feature. Therefore, along with the mapping relation in (8), the following evaluation procedure in (12) shows that the major place feature, i.e., Labial or Coronal, remains intact in loan adaptation in Japanese. That is, the optimal output $/ \phi /$ is bilabial which shares the Labial feature with the labio-dental input /f/, just like the $/ \theta / \rightarrow / \mathrm{s} /$ mapping sharing the Coronality.

\begin{tabular}{|l|l:l:l|l|}
\hline $\mathrm{f}$ & *Str & Max & Ident[cont & Ident[dental \\
& uct & - & ] \\
& & e & & \\
\hline \hline a. f & $* !$ & & & \\
\hline b. h & & $* !$ & & $*$ \\
\hline c. $\phi$ & & & & $*$ \\
\hline d. p & & & $* !$ & $*$ \\
\hline
\end{tabular}

The dual property of labiality and continuancy of the Japanese fricative can be easily found in the orthographic representation in Japanese, in which a foreign /f/ is adapted with $\langle\phi u\rangle$ フ followed by lowercase writing [13]. That is, the quality of a vowel following an /f/ is preserved by the lowercase writing, while the friction property of /f/ is reflected in $/ \phi /$ in the orthographic representation $\langle\phi \mathrm{u}\rangle$. (An $/ \mathrm{f} /+\mathrm{C}$ cluster is split by the /u/ (more accurately /u/) epenthesis which produces the $\langle\phi u\rangle$ orthographically and, thus not acquiring lowercase writing) [13].

(13) a. $/ \mathrm{f} /+\mathrm{V} \rightarrow\langle\phi \mathrm{u}>+$ lowercase writing

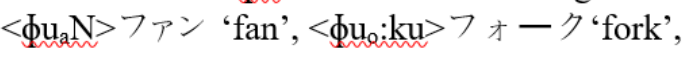
$<\phi u_{j u v} z i_{j o N} N>$ フューション 'fusion'

b. $/ \mathrm{f} /+\mathrm{C} \rightarrow<\mathrm{fu}>+\mathrm{C}$

'French',

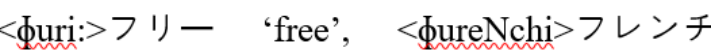

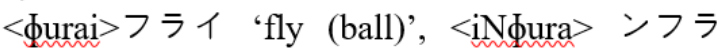
'infra(structure)'

\begin{tabular}{|l|l|}
\hline $\begin{array}{l}/ \mathrm{fæ}, \mathrm{fa}, \mathrm{f} \Lambda / \rightarrow \\
\left\langle\phi \mathrm{u}_{\mathrm{a}}\right\rangle\end{array}$ & $\begin{array}{l}\left\langle\phi \mathrm{u}_{\mathrm{a}} \mathrm{N}\right\rangle \text { ファン 'fan', } \\
\left\langle\phi \mathrm{u}_{\mathrm{a}} \mathrm{Ndo}\right\rangle \text { ファンド } \\
\text { 'fund' }\end{array}$ \\
\hline$/ \mathrm{fe} / \rightarrow\left\langle\phi \mathrm{u}_{\mathrm{e}}\right\rangle$ & $\left\langle\phi \mathrm{u}_{\mathrm{e}}: \mathrm{su}\right\rangle$ フェース 'face', \\
& $\left\langle\phi \mathrm{u}_{\mathrm{e}}:\right.$ minizumu $>$ エ \\
& ズム 'feminism' \\
\hline
\end{tabular}




\begin{tabular}{|c|c|}
\hline$/ \mathrm{fi} / /\left\langle\left\langle\mathrm{u}_{\mathrm{i}}\right\rangle\right.$ & $\begin{array}{l}\left\langle\phi \mathrm{u}_{\mathrm{o}}: \mathrm{ku}\right\rangle \text { フォーク 'fork', } \\
\left\langle\phi \mathrm{u}_{\mathrm{i}} \mathrm{ni}_{\mathfrak{s}} \mathrm{i}_{\mathrm{ju}}:>\text { フィニッシュ }\right. \\
\text { 'finish' }\end{array}$ \\
\hline$/ \mathrm{fo} / \rightarrow\left\langle\phi \mathrm{u}_{\mathrm{o}}\right\rangle$ & $\begin{array}{c}\left\langle\phi \mathrm{u}_{\mathrm{o}} \mathrm{Nto}>\text { フォント }\right. \\
\text { 'font', } \\
\left\langle\phi \mathrm{u}_{\mathrm{o}} \mathrm{Nde}_{\mathrm{ju}}:>\text { フォンデュ }\right. \\
\text { — 'fondue } \\
\text { (F.)' }\end{array}$ \\
\hline $\begin{array}{r}/ \mathrm{fu} / \rightarrow<\mathrm{fu}> \\
\left(*<\mathrm{fu}_{\mathrm{u}}>\right)\end{array}$ & 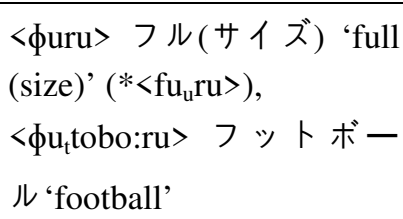 \\
\hline
\end{tabular}

Employing the basic framework of Optimality Theory, we now show the crucial role of the major Place (i.e., Labiality) preservation as the Max-Place constraints requires that the input place property (i.e., major place property) should have a correspondent (somewhere) in the output [14]. (Note that the inserted the Japanese high back vowel is unrounded /w/. Moreover, the constraint, $*[\mathrm{p}$, requires the prohibition of an initial $/ \mathrm{p} /$ in Japanese, except in onomatopoeic words).

(15) English /f/ $\rightarrow$ Japanese / $\phi /$ 'free'

\begin{tabular}{|c|c|c|c|c|c|c|}
\hline fri & Struct & $* \mathrm{CC}$ & $\begin{array}{l}\text { Max- } \\
\text { :Place }\end{array}$ & $\begin{array}{l}\text { Ident- } \\
\text { cont }\end{array}$ & $*[p$ & Dep \\
\hline a. fri & $* !$ & * & 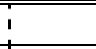 & 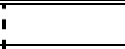 & & \\
\hline b. huuri & & & $* !$ & & 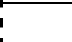 & * \\
\hline c.фuri & & & 工 & & I & $*$ \\
\hline d. puri & & & 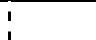 & $* !$ & $*$ & * \\
\hline
\end{tabular}

In this tableau, we observe the important role of Max-Place and Ident[cont] in the adaptation of /f/ as $/ \phi /$, by which the third candidate is selected as the final output. In the following section, however, we will observe the dominance of Max-place over Ident[cont], as the constraint ranking may differ from language to language.

\subsection{Decomposition of the labial / $f$ / in Korean adaptation}

According to Ahn [2022 to appear)0 Korean loan adaptation of the labial /f/ shows how the dual membership of the Japanese fricative is reflected in Korean. There are two types of English loan adaptation in Korean, i.e., the modern direct borrowing and the old indirect borrowing through Japanese, showing different phonemic mapping processes. The following shows that, unlike the /f/ $\rightarrow / \mathrm{p}^{\mathrm{h}} /$ mapping in "direct" English loanwords, the indirect loanwords take $/ \mathrm{h} /$ but it is followed by an /w/ for labiality.

\begin{tabular}{|l|l|l|}
\hline $\begin{array}{l}\text { English } \\
\text { words }\end{array}$ & $\begin{array}{l}\text { Indirect loans } \\
(\mathrm{Old})\end{array}$ & $\begin{array}{l}\text { Direct loans } \\
(\text { Modern})\end{array}$ \\
\hline \hline family & $\begin{array}{l}\text { hwemiri } \\
\text { 훼미리 }\end{array}$ & $\begin{array}{l}\mathrm{p}^{\mathrm{h}} \text { milli } \\
\text { 패밀리 }\end{array}$ \\
\hline
\end{tabular}

\begin{tabular}{|c|c|c|c|}
\hline fitness & $\begin{array}{l}\text { hwit }^{\mathrm{h}} \\
\text { 휘트 }\end{array}$ & & $\begin{array}{l}\mathrm{p}^{\mathrm{h}} \mathrm{it}^{\mathrm{h}} \text { inisi } \\
\text { 피트 니스 }\end{array}$ \\
\hline fantasy & $\begin{array}{l}\text { hwan } \\
\text { 환타 }\end{array}$ & & $\begin{array}{l}\mathrm{p}^{\mathrm{h}} \text { ant }{ }^{\mathrm{h}} \mathrm{aji} \\
\text { 판타지 }\end{array}$ \\
\hline fan & huan & 후앙 & $\mathrm{p}^{\mathrm{h}}$ æn 팬 \\
\hline fry & hurai & 후라이 & $\begin{array}{l}\mathrm{p}^{\text {hi }} \mathrm{rai} \\
\text { 프라이 }\end{array}$ \\
\hline free & huri & 후리 & $\mathrm{p}^{\mathrm{hi}} \mathrm{ri}$ 프리 \\
\hline
\end{tabular}

As shown in the following figures, the labiality of the Japanese / $\phi$ / (or the English /f/) is faithfully preserved in Korean loan adaptation (Lar and [SG] represent "Laryngeal" and [spread glottis], respectively).

(17) a. Old indirect loan:<smiles>O=C(O)C1CCCCC1=O</smiles>

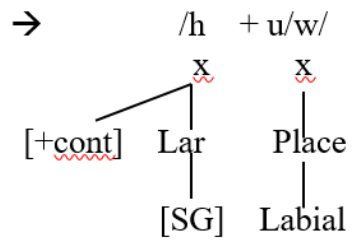

b. New direct loan:

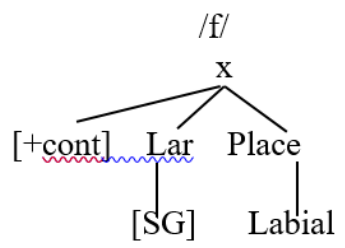

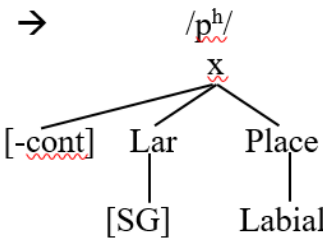

The illustrated figures show that the preservation of the Place property appears to be the main factor, in both types of loan adaptation, whereas the continuant property is not crucial in interlanguage mapping. In old indirect loan adaptation, the Japanese fricative is decomposed into two separate segments as the corresponding $/ \mathrm{h} /$ does not have the labiality. On the contrary, there is no need for decomposition for recent direct loan adaptation, since the labiality of the English fricative /f/ is preserved in the labial stop $/ \mathrm{p}^{\mathrm{h}} /$. The $/ \mathrm{f} / \rightarrow$ the aspirated $/ \mathrm{p}^{\mathrm{h}} /$ mapping also shows that the voicelessness of $/ \mathrm{f} /$ is preserved in $/ \mathrm{p}^{\mathrm{h}} /$ as the [SG] property (by aspiration). The German loanword, Pfizer 'Name of a pharmaceutical company' is written as 화이자 hwaija. In recent loanwords, however, /pf/ is adapted as $/ \mathrm{p}^{\mathrm{h}} /$ as in (Michelle) Pfeiffer 'An American actress' $\rightarrow$ 파이퍼 $p^{h}$ aip ${ }^{h}$.

Employing the framework of Optimality Theory, we now observe the crucial role of the major Place (i.e., Labiality) preservation. Moreover, we invoke the following faithfulness constraint for the bifurcation of the labial segment in loan adaptation, e.g., $/ \phi / \rightarrow / \mathrm{hu} /$ or /hw/.

(18) Linearity The output reflects the precedence structure of the input, and vice versa. [Kager 1999].

This constraint discourages any discrepancy in 
precedence between input and output. Thus, the bifurcation violates Linearity, rather than Dep, since it is different from segmental epenthesis.

$$
\text { Input: } h_{i \sim} \phi_{1,2} / \mid
$$

(20) Old loan adaptation: Indirect loan from AngloJapanese

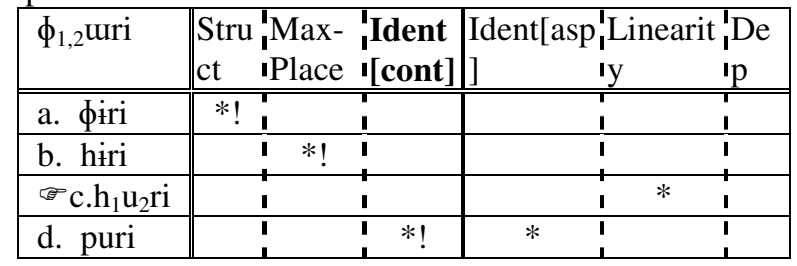

The tableau shows how the optimal output is selected by the interaction of the participating constraints. (Here, $\phi_{1}$ indicates the continuancy, while $\phi_{2}$ the labiality). The first constraint Struct eliminates the non-phonemic $/ \phi /$ in (20a), while Ident[cont] takes out (20d) having the initial [-cont] /p/. Then the Max-place removes the second candidate due to the lack of the input labiality in the output. As a result, the third candidate appears as the optimal output although it violates the lower ranking constraint Linearity, due to the bifurcation (i.e., decomposition) of the input labial segment $/ \phi /$ as $/ \mathrm{hu} /$. (The unrounded Japanese vowel /u/ is mapped to the corresponding unrounded Korean $/ \mathbf{i} /$, rather than the rounded $/ \mathrm{u} /$ ).

On the other hand, the new loan adaptation pattern shows the different output, in which the violation of Ident[cont] (bold-faced) is tolerated in the optimal output. We may think of a possible candidate */piri/ but it can be eliminated by invoking a new constraint Ident[aspirated] as all voiceless fricatives are [+aspirated], and other sounds are [-aspirated] by default.

(21) New loan adaptation: direct borrowing for 'free'

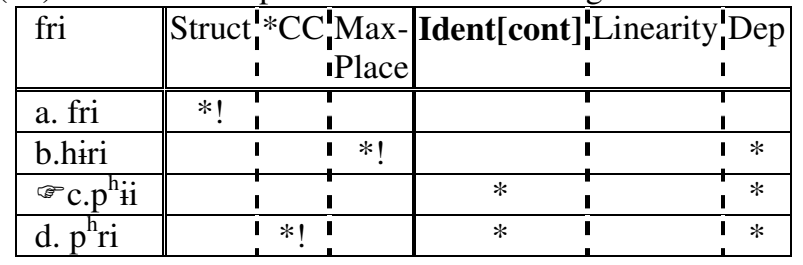

This tableau shows that we need to apply the constraint ranking differently, depending on the origin of the input. Therefore, the constraint ranking could be different even within the same language, as well as in different languages.

(22) Japanese loan adaptation $\rightarrow$ Max-Place, Ident[cont] $>>$ Linearity

Korean adaptation $\rightarrow$ Indirect loan: Max-Place, Ident[cont] $>>$ Linearity

Direct loan: Max-Place

>> Ident[cont], Linearity
This change of the constraint ranking can also be found in the adaptation of other fricatives. For example, the English $/ \theta /$ in thank you was adapted as $/ \mathrm{s} /$ in the past, but as $/ t /$ in modern times. The following tableaux show the inviolability of Max-place and Ident[cont] in the old adaptation. Moreover, we observe the demotion of Ident[cont] and the promotion of Ident[strid] in the new loan adaptation. As a consequence, the Max-Place dominates Ident[cont].

(23) Old loan adaptation: Indirect loan from Anglo-

\begin{tabular}{|c|c|c|c|c|}
\hline$\theta$ & Struct & $\begin{array}{l}\text { 'Max- } \\
\text { IPlace }\end{array}$ & $\left.\right|_{1} ^{1} I d e n t[\operatorname{cont}]$ & Ident[strident] \\
\hline $\begin{array}{c}\text { a. } \theta \\
\end{array}$ & $* !$ & $\bar{T}$ & $\bar{T}$ & \\
\hline b. $\mathrm{h}$ & & I $\quad * !$ & 1 & \\
\hline C. S & & 1 & 1 & $*$ \\
\hline d. $\mathrm{t}$ & & I & $* !$ & \\
\hline
\end{tabular}
Japanese

\begin{tabular}{|c|c|c|c|c|}
\hline$\theta$ & Struct & $\begin{array}{l}\text { IMax- } \\
\text { 'Place }\end{array}$ & IIdent[strident] & Ident[cont] \\
\hline a. $\theta$ & $* !$ & I & i & \\
\hline b. h & & t*! & $T$ & \\
\hline c. S & & 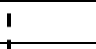 & $* !$ & \\
\hline $\mathrm{d} . \mathrm{t}$ & & 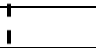 & 1 & * \\
\hline
\end{tabular}

(24) New loan adaptation: direct borrowing for 'free'

These examples show that the constraint ranking may change, depending on the level of loan adaptation, i.e., earlier and later loans. And this kind of ranking change is not allowed in the classic Optimality Theory. Various studies [15, 16], however, pointed out the problems occurring in the parallelism of "classic" Optimality Theory. Our current analysis also shows the empirical advantage of the so-called "Stratal OT" (BermúdezOtero 2018) due to the necessity of the constraint reranking based on the level of loan adaptation. Considering that there are at least two different prosodic levels in French Prosodic Structures, AP, IP and eventually ip, Ahn \& Martin (2019) employed the cyclic (or stratal) application of constraints in Optimality Theory, in which we posited a re-ranking mechanism in each evaluation cycle, i.e., different constraint ranking at the AP and IP levels.

Moreover, we can refer to the Core-Periphery model of [17], which utilizes reranking of the faithfulness constraints between different lexical strata. Adopting the basic concept of this multi-stratal model of constraint interactions, we thus posit the following model for the adaptation of the fricatives in Korean.

(25) Stratal organization of the constraints

\begin{tabular}{|l|}
\hline Foreign words: \\
Max-Place, Ident[cont], Linearity (all inviolable) \\
\hline New direct loans: \\
Max-Place, $>>$ Ident[cont], Linearity \\
\hline Old indirect loans: \\
Max-Place, Ident[cont]>> Linearity \\
\hline Native vocabulary: \\
\hline
\end{tabular}




\section{Further extension: decomposition of $/ f /$ in Yakut}

A similar case of consonantal decomposition, i.e., additional place (i.e., labial) specification, can be found in the Sakha language (often called Yakut). Yakut is a Turkic language with about 450,000 speakers in northern Russia. It is spoken mainly in the Sakha Republic (Yakutia), and also in the Khabarovsk Region, and in Irkutsk and Magadan provinces. For example, lacking the labial fricative /f/ in the phonemic inventory, the Yakut language often adapts /f/ as /p/ in Russian loanword adaptation, so that the labiality of /f/ can be preserved in the output $/ \mathrm{p} /$, while the [continuant] feature is lost. As a result, the /p/ and /f/ of Russian loanwords are neutralized in Yakut.

\section{(26) Russian /f/ $\rightarrow$ Yakut /p/ \\ Afonja /aponja/ 'male name' \\ Marfa /ma:ppa/ 'female name' \\ telefon /telepøn/ 'telephone'}

Yakut, however, has a strong phonotactic restriction banning / $/ \mathrm{p}$ in the initial position. Therefore, the initial $/ \mathrm{p} /$ in Russian loanwords is adapted as /b/ in Yakut, so that $/ \mathrm{p} /$ and $/ \mathrm{v} /$ are neutralized as $/ \mathrm{b} /$.

(27) Initial /p/ avoidance: Initial /p/ in Russian $\rightarrow / \mathrm{b} /$ in Yakut

$\begin{array}{lll}\text { Pavel } & \text { bajbal } & \text { 'Male name' } \\ \text { ponedel'nik } & \text { benidiennik } & \text { 'Monday' } \\ \text { perevoz } & \text { berebies } & \text { 'transportation' } \\ \text { parus } & \text { baaris } & \text { 'sail' } \\ \text { petfat' } & \text { betfeet } & \text { 'stamp' } \\ \text { platok } & \text { bilaat } & \text { 'shawl' } \\ \text { plen } & \text { bilien } & \text { 'captivity' } \\ \text { plita } & \text { biliite } & \text { 'stove' } \\ \text { plot } & \text { boluot } & \text { 'float' } \\ \text { plotnik } & \text { boluotunn'uk } & \text { 'carpenter' } \\ \text { potexa } & \text { betiexe } & \text { 'fun' } \\ \text { prazdnik } & \text { biraahinn'tk } & \text { 'holiday' } \\ \text { proverka } & \text { berebierke } & \text { 'check' } \\ \text { cf. vata } & \text { baata } & \text { 'cotton' } \\ \text { vedro } & \text { biedere } & \text { 'bucket' }\end{array}$

As the /f/ $\rightarrow / \mathrm{p} /$ mapping is not permitted in an initial position, the Russian /f/ is often decomposed as "/s/ + the front round $/ y /$ " in loanword adaptation in Yakut (i.e., mostly proper names). The Russian loanword adaptation is quite limited in the Yakut speaking region, due to the growing dominance of the Russian language. (The sequence $/ \hat{y} \varnothing /$ is one of the four diphthongs in Yakut, i.e., /ie, ŷ $\varnothing$, tạ, uo/ [18].

\section{(28) Russian /f/ $\rightarrow$ Yakut /sy/}

e.g., Fjodor $\rightarrow$ /syøder/ 'male name'

Fjokla $\rightarrow$ /syøkytgtge/ 'female name'

Fjodora $\rightarrow$ /syødyøre/ 'female name'

(cf. Febron'a $\rightarrow$ hoboroos 'female name')
Employing the feature-geometric framework, the decomposition of the labial fricative /f/ can be illustrated as follows. (The empty place node for $/ \mathrm{s} /$ will be filled in by the default Coronal specification.)

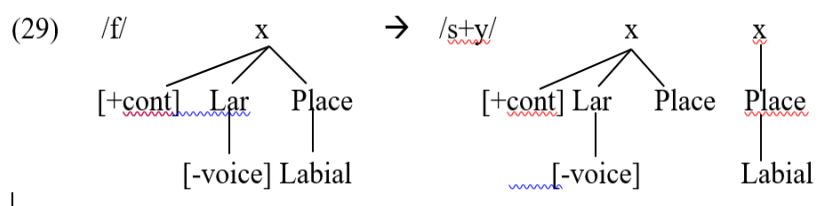

The figures in (29) show that the labial fricative /f/ is decomposed as a fricative $/ \mathrm{s} /$ and a round (i.e., labial) vowel, so that both the place and manner (i.e., [continuant]) properties can be preserved in the output. This process is akin to the decomposition of the Japanese $/ \phi /$ in Korean loan adaptation (i.e., as /hu/ or /hw/), in which the labiality of the input consonant is realized in the next (epenthetic) round vowel/glide, rather than in the corresponding consonant in the output.

The following tableaux show that the decomposition of /f/ in Yakut also reveals the crucial role of Max-Place constraint, rather than Ident-Place, as Max-Place has wider application preserving the corresponding place feature somewhere in the output, while Ident-Place requires the place preservation in the corresponding consonant.

(30) Initial /f/

\begin{tabular}{|c|c|c|c|c|c|c|}
\hline $\mathrm{f}_{1,2 \mathrm{j} \text { jodor }}$ & $\begin{array}{l}\text { Stru } \\
\text { ct }\end{array}$ & & $\begin{array}{l}\text { Max- } \\
\text { :Place } \\
\end{array}$ & $\begin{array}{l}\text { Ident[ } \\
\text { labial] }\end{array}$ & $\begin{array}{l}\text { Ident } \\
{[\text { cont }} \\
]\end{array}$ & $\begin{array}{l}\text { Linearit } \\
y \\
y\end{array}$ \\
\hline a. fjodor & $* !$ & & ' & & & i \\
\hline b.pjodor & & $* !$ & & & $*$ & \\
\hline c. sjodor & & & $* !$ & $*$ & & 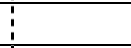 \\
\hline d. $\mathrm{s}_{1} \mathrm{y}_{2}$ odor & & & 1 & $*$ & & $*$ \\
\hline
\end{tabular}

(31) Non-initial /f/

\begin{tabular}{|c|c|c|c|c|c|}
\hline telef $_{1,2}$ on & $\mid \begin{array}{l:l}\text { Stru } & *[\mathrm{p} \\
\mathrm{ct} & \end{array}$ & $\begin{array}{l}\text { Max- } \\
\text { Place }\end{array}$ & \begin{tabular}{|l|} 
Ident \\
[labial \\
]
\end{tabular} & $\begin{array}{l}\text { Ident } \\
{[\text { cont }]}\end{array}$ & $\begin{array}{l}\text { Lineari } \\
\text { ty }\end{array}$ \\
\hline a. telefon & $* !$ & & & & \\
\hline b. teles ${ }_{1} \mathrm{y}_{2} \mathrm{on}$ & & & $*$ & & $*$ \\
\hline c. teleh $\mathrm{y}_{2} \mathrm{On}$ & & & $*$ & & $*$ \\
\hline d. telepon & 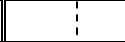 & 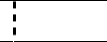 & & $*$ & \\
\hline
\end{tabular}

In both cases, we observe the dominance of Max-Place over the other faithfulness constraints, Ident[labial], Ident[cont], and Linearity.

This mapping by decomposition, however, may have exceptions as shown in (28). The Russian female name Febron'a, for example, is adapted as /hoboroos/ without decomposition, in which, the Max-Place constraint seems to be suppressed. Nevertheless, we notice that the initial vowel /e/ of the input is realized as $/ 0 /$ in the output due to the backness vowel harmony of the Yakut language. As a result, it is argued that the labiality of /f/ is still preserved in the round vowel /o/ of the output. Moreover, the decomposition in Yakut can be extended to the adaptation of stressed vowels, especially the stressed Russian /o/ which is decomposed as a diphthong 
/uo/ in Yakut. We can find abundant examples from the other Russian names [32a] or other common nouns [32b] adapted in Yakut.

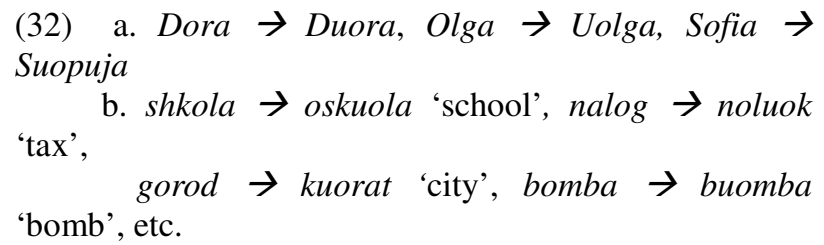

These examples show that the longer duration of a stressed vowel is adapted as a diphthong that still preserves the major place feature, i.e., labiality or roundness.

\section{Conclusion}

So far we have discussed various cases of consonantal decomposition in interlanguage mapping within the framework of Optimality Theory. During the discussion, we have shown that the preservation of the (major) place property takes the most crucial role in the segmental decomposition in interlanguage mapping. As for the Japanese loan adaptation of /f/, we posited this Japanese fricative as $/ \phi /[1]$ preserving the labiality and show the inviolability of the constraint Max-Place. Then we compared the indirect adaptation of the English /f/, i.e., via Anglo-Japanese $/ \phi /$, with the direct loan adaptation in Korean. In the indirect (old) adaptation, the labial fricative $/ \phi /$ is decomposed as the fricative $/ \mathrm{h} /$ and the labial vowel $/ \mathrm{u} /($ or $/ \mathrm{w} /$ ), while the direct (new) loan pattern shows the /f/ $\rightarrow / \mathrm{p}^{\mathrm{h}} /$ mapping. Here we observed not only the inviolability of Max-Place but also the demotion of Ident[cont] on the level of direct loan adaptation. We thus support the Stratal OT [2], regarding the levels of adaptation. Supporting the inviolability of Max-Place, we also discussed how the Russian /f/ is decomposed in the loan adaptation in Yakut.

\section{References}

1. G. Iverson, Some roles of phonology in second language acquisition. (Ms. University of Wisconsin-Milwaukee)

2. K. René, Optimality Theory (Cambridge University Press, 1998)

3. R. Bermúdez-Otero, Stratal phonology. In $\mathrm{S}$. Hannahs and A. R. K. Bosch (Eds.), The Routledge Handbook of Phonological Theory. Pp. 100-134.( Abingdon: Routledge, 2019)

4. D. Silverman, Multiple scansions in loanword phonology: evidence from Cantonese. Phonology 9, 289-328 (1992)

5. C. Paradis, D. LaCharité, Preservation and minimality in loanword adaptation. Journal of Linguistics 33, 379-430 (1997)

6. Sh. Peperkamp, E. Dupoux, Reinterpreting loanword adaptation: the role of perception. Proceedings of the $15^{\text {th }}$ International Congress of Phonetic Sciences, 367-370 (2003)
7. D. LaCharité, C. Paradis, Category preservation and proximity versus phonetic approximation in loanwords adaptation. Linguistic Inquiry 36, 223258 (2005)

8. A. Kochetov, Phonology and phonetics of loanword adaptation Russian place names in Japanese and Korean. Toronto Working Papers in Linguistics 28, 159-174 (2008)

9. S.-C. Ahn and J. Lee, Loan adaptation in laryngeal features. In Rafaella Folli and Christiane Ulbrich (eds.) Interfaces in Linguistics: New Research Perspectives (Oxford Studies in Theoretical Linguistics). Pp. 299-317. Oxford University Press (2011)

10. S.-C. Ahn, Korean Phonology (London: EAP, 2010).

11. L. Campbell, Historical Linguistics (Edinburgh University Press, 2013).

12. G. N. Clements, The Geometry of Phonological Features, Phonology Yearbook 2, 225-252 (1985)

13. G. N. Clements and E. Hume, The Internal Organization of Speech Sounds. In John Goldsmith (ed.) Handbook of Phonological Theory, pp. 245-306 Oxford: Basil Blackwell (1995).

14. S.-C. Ahn and K. Egorova, Lowercase writing in loanword transliteration in Japanese. Manuscripta Orientalia. 27:1, 36-44. International Journal for Oriental Manuscript Research (2021)

15. L. Lombardi, Evidence for Max Feature Constraint from Japanese. University of Maryland Working Papers in Linguistics 7, 41-62 (1998)

16. Rubach, Jerzy, Polish palatalization in Derivational Optimality Theory, Lingua 113, 197-237 (2003)

17. S.-C. Ahn and Philippe Martin, On the emergence of the French Accentual Phrase. Vestnik 71:3, 5166. North-Eastern Federal University (2019)

18. J. Ito and A. Mester, The core-periphery structure of the lexicon and constraints on reranking. University of Massachusetts Occasional Papers 18: Papers in Optimality Theory, 181-209 (1995)

19. J. R. Krueger. Yakut Manual: Area Handbook, Grammar, Graded Reader, and Glossary, Uralic and Altaic Series. Bloomington: Indiana University (1962) 